\title{
Prediction and mitigation of traffic induced ground vibrations in an urban zone
}

\author{
M. Mhanna, M. Sadek \& I. Shahrour \\ Laboratory of Civil Engineering and geo-Environment ( $L G C g E)$, \\ University of Lille 1-Polytech-Lille, France
}

\begin{abstract}
Ground vibrations generated by heavy trucks and buses are a common source of environmental problem. They can reach levels that may cause nuisance to residents, damage to near-by structures, and perturbation in the functioning of sensitive equipment. These vibrations are produced mainly when the vehicle wheel's pass over a speed reducer such as a road hump or a speed cushion. This study aims to investigate the size and nature of these vibrations and suggests a suitable method to reduce the vibration levels. Using a half-car model with four degrees of freedom, the dynamic response of vehicle to the road irregularity is simulated. The equation of motion of the fully coupled system (vehicle-road unevenness) is solved step by step in the time domain, and then the resultant load is used in 3D numerical model to predict the traffic induced vibrations in the free field. The proposed model is validated and used to analyze the effect of different types of traffic calming on the vibrations levels in the free field. Furthermore, Numerical simulations are carried out to study the efficiency of trench barriers.

The results show that some road unevenness geometry under certain vehicle speed could result in very high dynamic effects and thus a perceptible level of traffic induced vibration. A significant vibration reduction can be achieved using a suitable measure like a trench barrier.
\end{abstract}

Keywords: traffic, vibration, prediction, numerical model, road irregularity.

\section{Introduction}

Vibrations induced by road traffic are a common concern in urban areas, annoyance and damage complaints are commonly expressed by the residents of near-by houses. A series of measurements of road traffic-induced vibrations have 
been conducted to analyze various problems related to these vibrations. Watts and Krylov [1] showed that the most of perceptible vibrations are produced by heavy vehicles and the vibration level increases with the vehicle speed and with the height and depth of pavement surface irregularity. D'Apuzzo and Crispino [2] and D'Apuzzo [3] expressed the vibration amplitude as a function of the road irregularity and vehicle speed using a modified Watts' formula. Hunaidi and Rainer [4] and Hunaidi et al. [5] tried to correlate the vibration characteristics (level and frequency content) to the vehicle suspension system and to the seasonal climate variation. Theoretical studies and numerical models have been proposed by many researchers. Lombaert and Degrande $[6,7]$ used the boundary element method in the frequency-wave number domain together with the BettiRayleigh reciprocal theorem to compute the dynamic response induced by moving vibration source. Shen [8] proposed a finite element model to investigate the characteristics of building vibrations induced by adjacent moving truck crossing random irregularities. $\mathrm{Xu}$ and Hong [9] showed that traffic-induced ground vibrations impede the normal operation of high-tech facilities by using a stochastic approach. Cao et al. [10] developed a Matlab code for solving the ground response subjected to moving loads. They reported that the ground vibration induced by moving load is of typical low-frequency problem controlled by the Rayleigh's wave velocity of the top soil layer. Moreover, Hajek et al. [11] reported that the vehicle axle load applied on the pavement due to a surface irregularity may be divided into two basic types: The suspended mass also called as the body bounce with a frequency in the range $(0.8-4 \mathrm{~Hz})$, and the axle hop with frequency in the range of $(8-15 \mathrm{~Hz})$. The time-domain finite element and finite difference methods are seldom used to simulate the free field vibrations induced by road roughness. This paper proposes a 3D combined discrete - finite element model to analyze the problem of traffic induced vibrations in soil and structure. This global approach could provide reliable answers in case of complex geometry with the presence of superstructure, soil stratification and could be used to analyze the efficiency of isolation barriers and preventive strategy.

\section{Numerical model and validation}

The numerical modeling includes two parts: Firstly, the dynamic axle load in the time domain resulting from pavement irregularity is determined using a discrete vehicle model. The resulting axle dynamic response of vehicle is then used in a $3 \mathrm{D}$ finite difference modeling to analyze the induced wave propagation.

\subsection{Vehicle axle load}

Half car model with four degree-of-freedom is firstly adopted in order to simulate the vehicle dynamic response to discrete irregularity as showed in fig. 1. This model has the main advantage of integrating the vehicle pitch motions, body motions and center of gravity effect. Furthermore, the differences between front and rear dampers and spring characteristics can be modeled properly. 


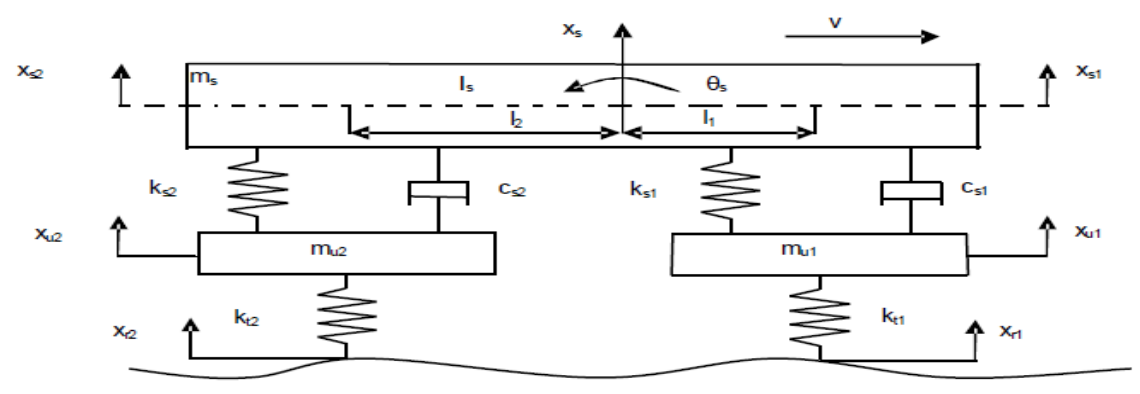

Figure 1: 4 DOF half car model of the vehicle.

The equations of motion for the vehicle body, front and rear wheels can be written as [17]:

$$
[M](\ddot{X})+[C](\dot{X})+[K](X)=(P)
$$

$[\mathrm{M}],[\mathrm{C}],[\mathrm{K}]$ are the matrix of mass, damping and rigidity respectively. $(\mathrm{P})$ is the interaction forces between the front and rear axle and the pavement, where:

$$
\mathrm{P}_{1}(\mathrm{t})=\mathrm{K}_{\mathrm{t} 1}\left(\mathrm{x}_{\mathrm{u} 1}(\mathrm{t})-\mathrm{x}_{\mathrm{r} 1}(\mathrm{t})\right) \quad \mathrm{P}_{2}(\mathrm{t})=\mathrm{K}_{\mathrm{t} 2}\left(\mathrm{x}_{\mathrm{u} 2}(\mathrm{t})-\mathrm{x}_{\mathrm{r} 2}(\mathrm{t})\right)
$$

$\mathrm{k}_{\mathrm{t} 1}$ and $\mathrm{k}_{\mathrm{t} 2}$ are the front/rear stiffness, $\mathrm{x}_{\mathrm{u} 1}$ and $\mathrm{x}_{\mathrm{u} 2}$ are the vertical displacement of the vehicle body at the front/rear suspension location. $x_{r 1}$ and $x_{r 2}$ are the irregularity excitation from the pavement surface at the location of front/rear tire. Detailed information about eqn (1) is provided by Law et al. [12].

\subsection{Validation of the proposed model}

The proposed model is validated using a field experimental study conducted by Lombaert and Degrande [6] who measured free field vibrations due to passage of the Volvo FL6 truck on artificial road unevenness at vehicle speed between 23 and $58 \mathrm{~km} / \mathrm{h}$.

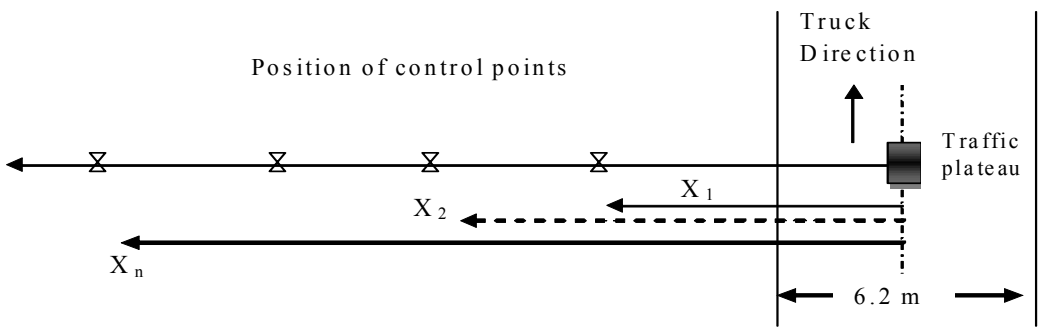

Figure 2: General road layout used in the experimental study [6]. 
Fig. 2 shows the cross section of the road and the control points used in field measurements. The artificial unevenness is taken as traffic plateau with two ramps and a flat mid section as illustrated in fig. 3 .

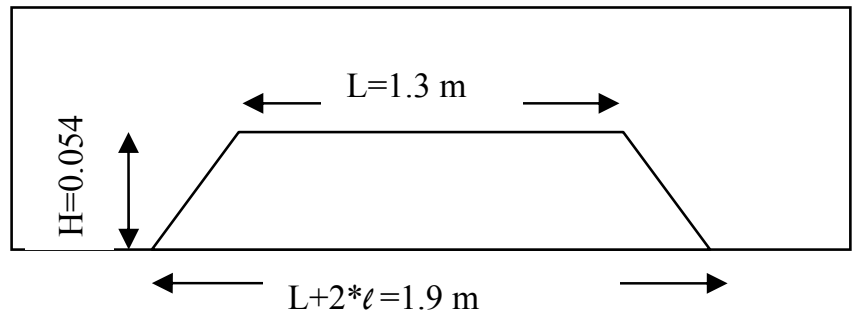

Figure 3: Longitudinal profile of the road unevenness.

The characteristics of road pavement, subgrade soil layers and the vehicle are illustrated in tables 1,2 and 3.

Table 1: Characteristics of road pavement layers.

\begin{tabular}{|c|c|c|c|c|}
\hline Layer type & $\mathrm{D}(\mathrm{m})$ & $v$ & $\rho\left(\mathrm{kg} / \mathrm{m}^{3}\right)$ & $\mathrm{E}(\mathrm{MPa})$ \\
\hline Asphalt & 0.15 & 0.33 & 2100 & 9150 \\
Crushed stone & 0.2 & 0.5 & 2000 & 500 \\
Crushed concrete & 0.25 & 0.5 & 1800 & 200 \\
\hline
\end{tabular}

Table 2: $\quad$ Characteristics of subgrade soil Layers.

\begin{tabular}{|c|c|c|c|c|}
\hline Layer & $\mathrm{D}(\mathrm{m})$ & $v$ & $\rho\left(\mathrm{kg} / \mathrm{m}^{3}\right)$ & $\mathrm{E}(\mathrm{MPa})$ \\
\hline 1 & 0.5 & 0.33 & 1900 & 57 \\
2 & 0.5 & 0.33 & 1900 & 133 \\
3 & 1.5 & 0.33 & 1900 & 223 \\
4 & 6 & 0.47 & 2000 & 322 \\
5 & $\infty$ & 0.47 & 2000 & 1288 \\
\hline
\end{tabular}

Table 3: $\quad$ Parameters of the vehicle model [7].

\begin{tabular}{|l|l|l|l|}
\hline $\mathrm{m}_{\mathrm{s}}=9000 \mathrm{~kg}$ & $\mathrm{k}_{\mathrm{s} 1}=0.32 \times 10^{6} \mathrm{~N} / \mathrm{m}$ & $\mathrm{c}_{\mathrm{s} 1}=10050 \mathrm{~N} \mathrm{~s} / \mathrm{m}$ & $\mathrm{m}_{\mathrm{u} 2}=600 \mathrm{~kg}$ \\
\hline $\begin{array}{l}\mathrm{I}_{\mathrm{s}}=35000 \\
\mathrm{kgm}^{2}\end{array}$ & $\mathrm{k}_{\mathrm{s} 2}=0.61 \times 10^{6} \mathrm{~N} / \mathrm{m}$ & $\mathrm{c}_{\mathrm{s} 2}=16000 \mathrm{~N} \mathrm{~s} / \mathrm{m}$ & $\mathrm{k}_{\mathrm{t} 2}=3 \times 10^{6} \mathrm{~N} / \mathrm{m}$ \\
\hline $\mathrm{m}_{\mathrm{u} 1}=400 \mathrm{~kg}$ & $\mathrm{k}_{\mathrm{t} 1}=1.5 \times 10^{6} \mathrm{~N} / \mathrm{m}$ & $\mathrm{L}_{1}=3.72$ & $\mathrm{~L}_{2}=1.49$ \\
\hline
\end{tabular}




\subsection{Axle load forces}

The equation of motion (1) is resolved using an explicit Runge-Kutta scheme in a Matlab program that calculates the vehicle axle load. The car parameters are summarized in Table 3. Eigen analysis gives the two eigen modes of the truck: 10.8 and $12.4 \mathrm{~Hz}$ which correspond to the front and rear axle hop; 1.9 and $1.4 \mathrm{~Hz}$ which correspond to the body bounce and pitch of the front and rear axle respectively. Fig. 4 displays the front axle load of the truck for two vehicle speeds $\mathrm{V}=30$ and $58 \mathrm{~km} / \mathrm{h}$.
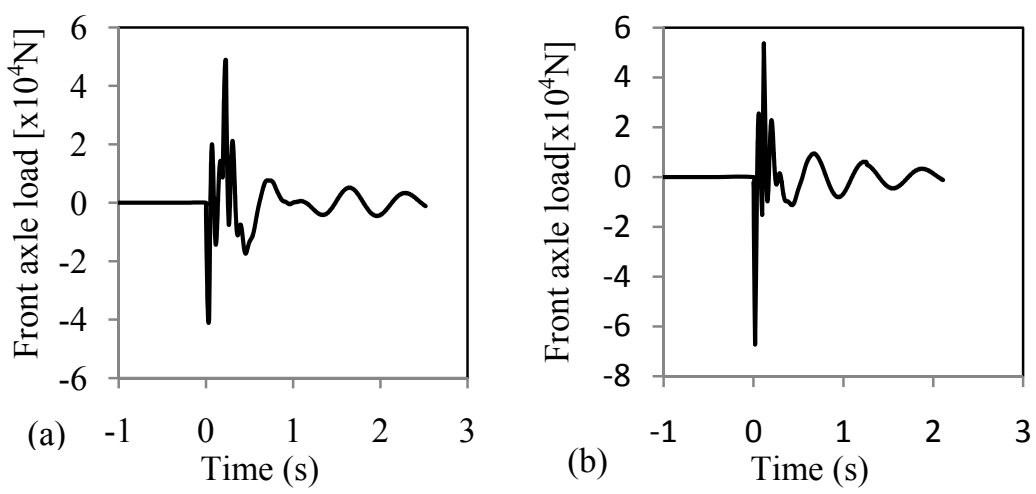

Figure 4: Time history of the front axle load for the passage of the vehicle on the road unevenness with the vehicle speed (a) $\mathrm{V}=30 \mathrm{~km} / \mathrm{h}$, (b) $\mathrm{V}=58 \mathrm{~km} / \mathrm{h}$.

\subsection{Finite difference modeling}

Numerical analyses are conducted using a finite difference scheme. Wave propagation induced by road traffic could be correctly described using viscoelastic model. In order to prevent wave reflection, viscous dashpots are

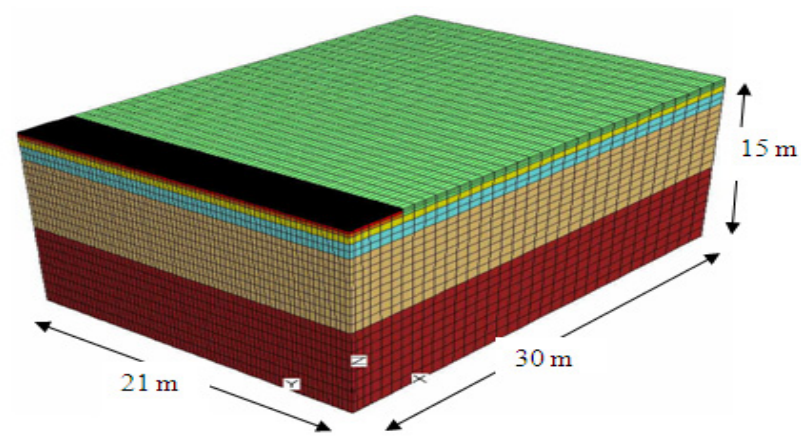

Figure 5: 3D Numerical mesh of the road and soil layers (53130 elements). 
used in the normal and shear directions at model boundaries. A general damping effect provided by Rayleigh damping has been introduced. The finite difference model used for the road structure and the soil surrounding is shown in fig. 5. The size of the model is $30 \times 21 \times 15 \mathrm{~m}^{3}$ (length/width/depth). The mesh sizes are refined near the applied forces $(0.3 \times 0.3 \times 0.15)$ and increase gradually with the distance from the source of vibration along the axe $\mathrm{X}$ and $\mathrm{Z}$. The model is symmetrical about the road centre (fig. 5).

The axle load depicted in the fig. 4 is applied as a pressure on the pavement. Fig. 6 compares the predicted velocity PPVz at a distance 8 and $16 \mathrm{~m}$ from the applied load, to measured velocity published in the reference [6]. A good agreement is observed between the measured and predicted velocities for both distances $\mathrm{X}=8 \mathrm{~m}$ and $\mathrm{X}=16 \mathrm{~m}$.
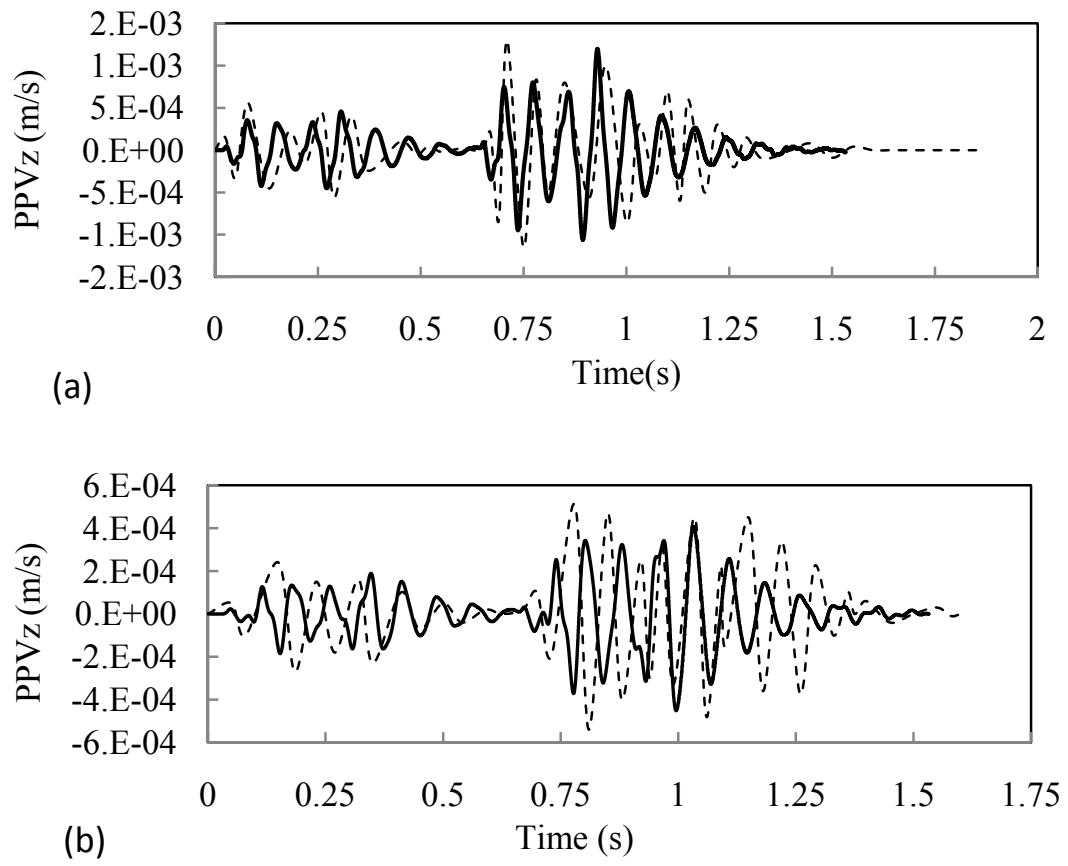

Figure 6: $\quad$ Time history of measured (dashed line) and predicted (solid line) free field velocity (PPVz) at $8 \mathrm{~m} \mathrm{(a),} \mathrm{and} 16 \mathrm{~m} \mathrm{(b)} \mathrm{from} \mathrm{the} \mathrm{applied}$ load at a vehicle speed $\mathrm{V}=30 \mathrm{~km} / \mathrm{h}$.

\section{The influence of road surface unevenness}

The road unevenness can be either local or global. For our model only the local unevenness will be taken into consideration. Three kinds of local road unevenness are taken in this study as shown in fig. 7. These speed reducers are selected according to the recommendation of French regulations CERTU [13]. 
The speed cushion has the total length of $2 \mathrm{~m}$ including two ramps of $0.5 \mathrm{~m}$, the traffic hump has a sinusoidal shape of $420 \mathrm{~mm}$ long, $50 \mathrm{~mm}$ high, while the wide trapezoidal traffic calming has a flat top part of $3 \mathrm{~m}$ and two ramps of length $1 \mathrm{~m}$.
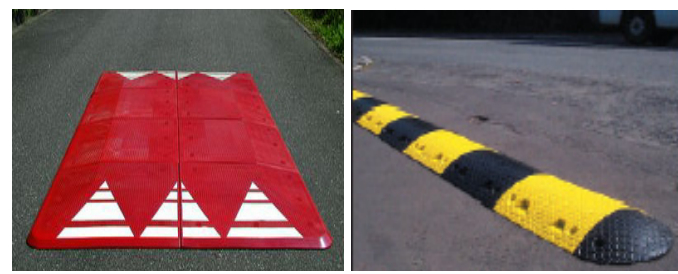

(case. 1) Speed cushion

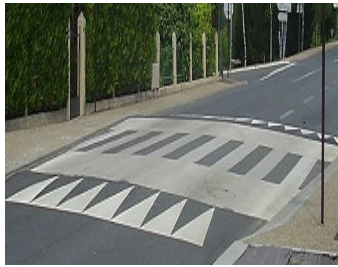

(case. 3) Trapezoidal

Figure 7: Different road unevenness tested in the study.

Figs. 8, 9 show the front axle loads and frequency content during the passage of the vehicle on these speed reducers at a speed of $36 \mathrm{~km} / \mathrm{h}$. It can be noticed that the frequency content has mainly two peaks: the first corresponds to the bitch and bounce mode and the second corresponds to the axle hop mode. In cases 1 and 3 the dominant frequency is about $2 \mathrm{~Hz}$ which corresponds to the pitch and bounce mode, while the dominant frequency in case 2 is about $10 \mathrm{~Hz}$ which corresponds to the axle hop mode. In all cases, the frequency content is mainly situated below $20 \mathrm{~Hz}$. This result well agrees with measurements realized by Hunaidi and Rainer [4]. Table 4 summarizes the influence of the speed reducer on the free field particle velocity induced by the vehicle passage. It can be observed that the short hump (case 2) produces the highest response despite its lower height. Furthermore, the induced vibration in this case exceeds the threshold of vibrations allowed in urban areas. This result meets the recommendation of the UK department of transport which limits the height of humps used as traffic calming measure in the vicinity of building to $40 \mathrm{~mm}$

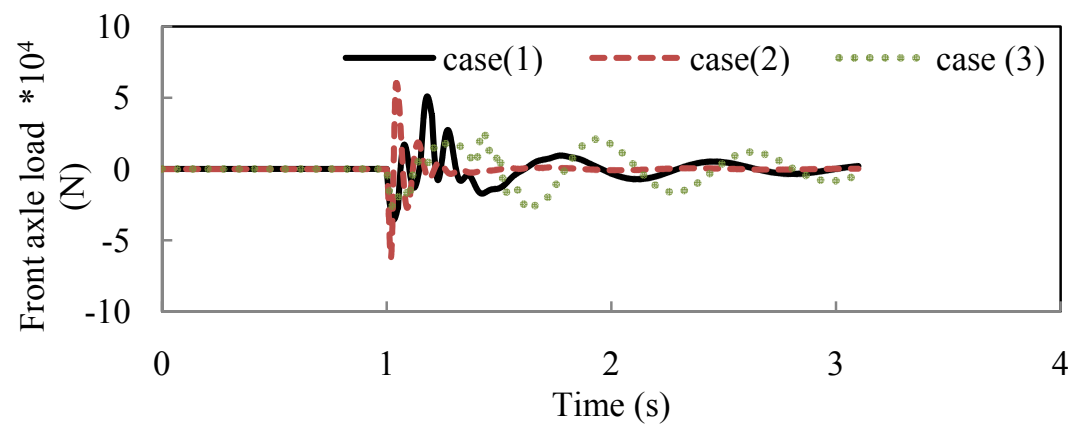

Figure 8: Time history of the front axle load induced by different speed reducers: $\mathrm{V}=36 \mathrm{~km} / \mathrm{h}$. 
(Watts et al. [14]). The comparison between the speed cushion (case 1) and the trapezoidal traffic calming (case 3) shows that the ramp slope is of significant importance. Despite a greater height in the latter case, the vibration level is greater in the former. It is mainly attributed to a steeper slope of $12 \%$ in the case of speed cushion in comparison of $10 \%$ in case 3 . In many countries including Belgium, a slope of 5\% is imposed for road humps frequently used by buses and heavy traffic as explained by Lombaert [15].

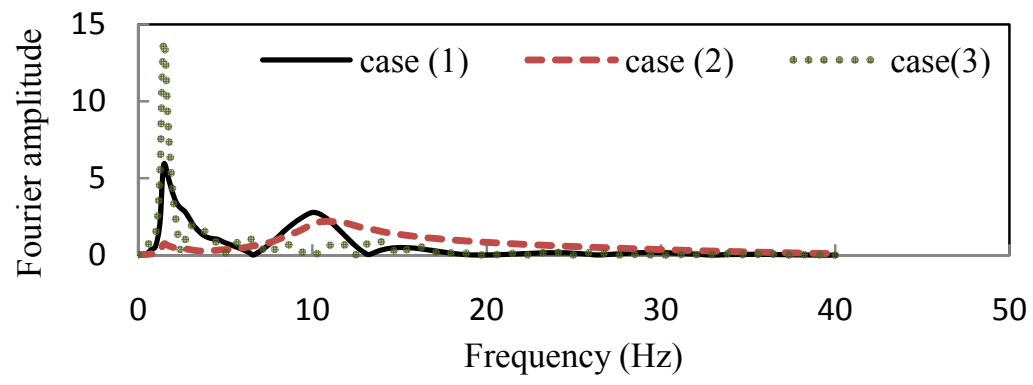

Figure 9: Frequency content of the front axle load induced for different speed reducers: $\mathrm{V}=36 \mathrm{~km} / \mathrm{h}$.

Table 4: $\quad$ PPVz $(\mathrm{mm} / \mathrm{s})$ in the free field for different speed reducers $V=36$ $\mathrm{km} / \mathrm{h}$.

\begin{tabular}{|c|c|c|c|c|c|c|}
\hline \multirow{2}{*}{ case } & \multicolumn{7}{|c|}{ Distance from the road centre (m) } \\
\cline { 2 - 7 } & $\mathbf{4}$ & $\mathbf{8}$ & $\mathbf{1 2}$ & $\mathbf{1 6}$ & $\mathbf{2 0}$ & $\mathbf{2 4}$ \\
\hline $\mathbf{( 1 )}$ & 1.45 & 0.57 & 0.42 & 0.36 & 0.29 & 0.19 \\
\hline $\mathbf{( 2 )}$ & 6.48 & 2.46 & 2.08 & 1.97 & 1.52 & 0.93 \\
\hline $\mathbf{( 3 )}$ & 1.02 & 0.43 & 0.28 & 0.18 & 0.15 & 0.13 \\
\hline
\end{tabular}

\section{Vibration mitigation using trench barrier}

This section presents another application of the proposed model related to vibration mitigation. The efficiency of the trench barrier in screening the vibrations generated by a heavy vehicle is evaluated. A trench barrier is installed at a distance of $1 \mathrm{~m}$ from the source to reduce the ground vibrations, the trench is assumed to have a depth $d=\lambda / 2$ where $\lambda$ is the wavelength $(\lambda=10 \mathrm{~m})$. The width of trench is chosen as $\mathrm{w}=0.3 \mathrm{~m}$. A schematic illustration of the wave barrier system is depicted in fig. 10 . 


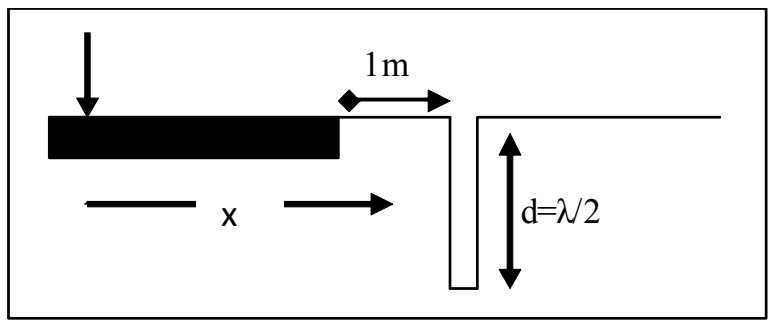

Figure 10: Schematic illustration of the wave barrier.

The reduction in the vibration levels is usually evaluated using the amplitude reduction ratio (Ar). This method firstly proposed by Wood (1968) consists in assessing (Ar) by normalizing the vertical amplitude of grounds surface with the wave barrier (PPVz) after, to the vertical amplitude of ground surface without the wave barrier, (PPVz) before.

$$
A r=\frac{P P V z(\text { After })}{P P V z(\text { Before })}
$$

A parametric analysis is conducted function of the stiffness of filling material relatively to the surrounding soil $(\mathrm{E} 1 \approx 60 \mathrm{Mpa})$. Two configurations of trench barriers are investigated: when $(\mathrm{E} 2 / \mathrm{E} 1>1)$ the trench is considered stiff, otherwise it is considered soft. The amplitude reduction ratio using a soft and rigid trench barrier is plotted in fig. 11 and fig. 12 respectively. It can be seen that

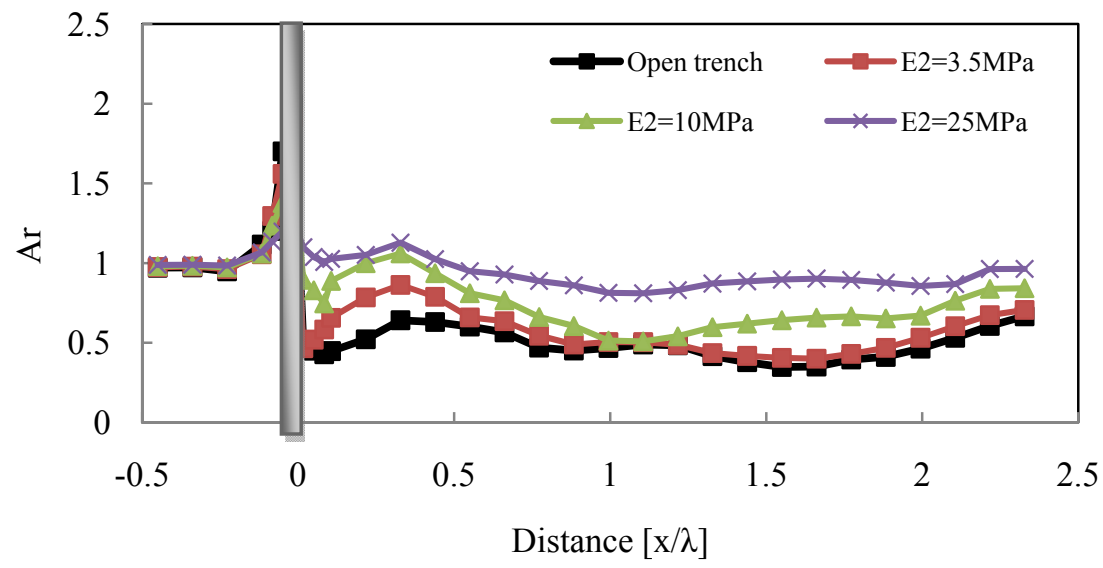

Figure 11: Amplitude reduction ration using soft barrier $(d=\lambda / 2)$. 


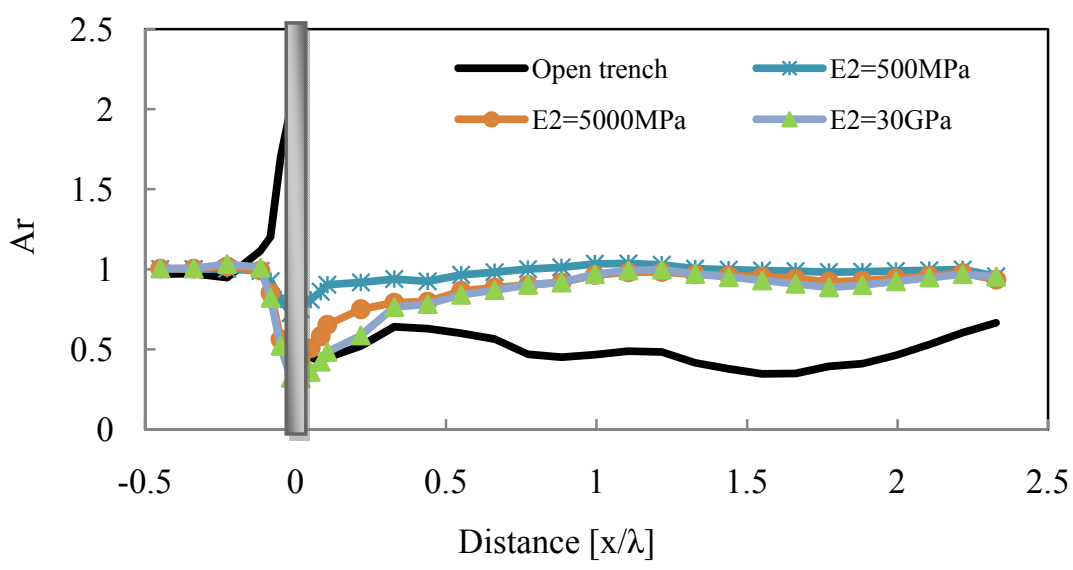

Figure 12: Amplitude reduction ration using stiff barrier $(\mathrm{d}=\lambda / 2)$.

a part of the wave energy is reflected in front of the soft trench and may increases the vibration levels. Contrary, no vibration amplification occurs in front of the stiff trench because the rigid material can transmit a significant part of the incident waves. When the trench depth is equivalent to a half of wavelength, the isolation effect of open trench is about (50\%). However, soft trench barriers are more efficient than stiff ones. The performance of trenches filled by a material with very small stiffness such as a soil-bentonite trench $(\mathrm{E} 2=3.5 \mathrm{MPa})$ is comparable to that of open trenches. On the other hand, the efficiency of isolation by using a stiff trench is limited to the vicinity of the trench (within $0.5 \mathrm{~d}$ behind the trench); its effect vanishes quickly with the distance behind the trench.

\section{Conclusion}

This paper included the validation a numerical model to analyze the traffic induced vibrations in the soil. The proposed approach is composed of discrete half car model together with a 3D finite difference modeling. This model is successfully validated using experimental measurements provided in the literature. This global approach could provide reliable answers in case of complex geometry with the presence of superstructure, soil stratification and could be used to analyze the efficiency of isolation barriers and preventive strategy. The current study illustrates that certain unevenness geometry can result in very high dynamic effects and consequently a perceptible level of traffic induced vibration may be produced. The efficiency of stiff and soft wave barriers as mitigation measures was also investigated. It is shown that a soft barrier with a length about half of the wavelength can reduce the vibration levels up to $50 \%$. Soft barriers were shown to be more efficient vibration countermeasure than stiff ones. 


\section{References}

[1] Watts, G.R., \& Krylov, V.V., Ground-borne vibration generated by vehicles crossing road humps and speed control cushions. Applied Acoustic. 59(3), pp. 221-236, 2000.

[2] D'Apuzzo, M. \& Crispino, M., Measurement and prediction of trafficinduced vibrations in a heritage building. Sound and Vibration. 246(2), pp. 319-335, 2001.

[3] D'Apuzzo, M., Some remarks on the prediction of road traffic induced ground-borne vibrations. 4th international SIIV congress, Palermo, Italy, 2007.

[4] Hunaidi, O, \& Rainer, J. H., Control of traffic-induced vibration in buildings using vehicle suspension systems. Soil Dynamics and Earthquake Engineering, 15(4), pp. 245-254, 1996.

[5] Hunaidi, O., Guan, W. \& Nicks, J., Building vibrations and dynamic pavement loads induced by transit buses. J. Soil Dynamics and Earthquake Engineering. 19(6), pp. 435-453, 2000.

[6] Lombaert, G. \& Degrande, G., Experimental validation of a numerical prediction model for free field traffic induced vibrations by in situ experiments. Soil Dynamics and Earthquake Engineering. 21(6), pp. 485497, 2001.

[7] Lombaert, G., and Degrande, G., The experimental validation of a numerical model for the prediction of the vibrations in the free field produced by road traffic. Sound and Vibration. 262(2), pp. 309-331, 2003.

[8] Shen, H. J., Finite element investigation of traffic induced vibrations. Sound and Vibration, 321(3-5), 837-853, 2009.

[9] Xu, Y.L., Hong, X.J., Stochastic modeling of traffic-induced building vibration. Sound and Vibration, 313(1-2), pp. 149-170, 2008.

[10] Cao, Y.M., Xia, H., \& Lombaert, G., Solution of moving-load-induced soil vibrations based on the Betti-Rayleigh Dynamic Reciprocal Theorem. Soil Dynamics and Earthquake Engineering, 30(6), pp. 470-480, 2010.

[11] Hajek, J., Blaney, C.T., \& Hein, D.K., Mitigation of Highway Traffic induced Vibration. Annual Conference of the Transportation Association of Canada: Charlottetown, Prince Edward Island, 2006.

[12] Law, S.S., Bu, J.Q., Zhu, X.Q. \& Chan, S.L., Vehicle axle loads identification using finite element method. Engineering Structures, 26, pp. 1143-1153, 2004.

[13] Centre d'études sur les réseaux, les transports, l'urbanisme et les constructions. Guide les ralentisseurs de type dos d'âne et trapézoïdale textes et recommandations, 1994.

[14] Watts, GR., Harris, G.J., \& Layfield, R.E., Traffic calming: vehicle generated ground-borne alongside speed control cushions and road humps. TRL Reports 235, 1997.

[15] Lombaert, G., Development and experimental validation of a numerical model for the free field vibrations induced by road traffic. Ph.D. Thesis, Catholic university of Leuven., Belgium, 2001. 